\title{
Global Trends in Cosmetics Use-Related Adverse Effects: A Bibliometric Analysis of Literature Published during 1957-2021
}

\author{
Manjula Nayak ${ }^{1}$, Dharmagadda Sreedhar ${ }^{1}$, Smitha S. Prabhu ${ }^{2}$ and Virendra S. Ligade ${ }^{1, *}$ \\ 1 Department of Pharmacy Management, Manipal College of Pharmaceutical Sciences, \\ Manipal Academy of Higher Education, Manipal 576104, Karnataka, India; \\ manjula.mcopsma1@learner.manipal.edu or nayakmanjula18@gmail.com (M.N.); \\ d.sreedhar@manipal.edu (D.S.) \\ 2 Department of Dermatology and Venereology, Kasturba Medical College, Manipal Academy \\ of Higher Education, Manipal 576104, Karnataka, India; smitha.prabhu@manipal.edu \\ * Correspondence: virendra.sl@manipal.edu or virendra123sl@gmail.com; Tel.: +91-820-2922482; \\ Fax: +91-820-2571998
}

check for updates

Citation: Nayak, M.; Sreedhar, D.; Prabhu, S.S.; Ligade, V.S. Global Trends in Cosmetics Use-Related Adverse Effects: A Bibliometric Analysis of Literature Published during 1957-2021. Cosmetics 2021, 8 , 75. https://doi.org/10.3390/ cosmetics 8030075

Academic Editors: Shazia Jamshed and Hazrina Hadi

Received: 19 June 2021

Accepted: 25 July 2021

Published: 24 August 2021

Publisher's Note: MDPI stays neutral with regard to jurisdictional claims in published maps and institutional affiliations.

Copyright: (c) 2021 by the authors. Licensee MDPI, Basel, Switzerland. This article is an open access article distributed under the terms and conditions of the Creative Commons Attribution (CC BY) license (https:// creativecommons.org/licenses/by/ $4.0 /)$.

\begin{abstract}
Cosmetic and beauty products, though not essential for physical health, go a long way in providing mental well-being and confidence, and hence are used substantially. Increasing utilization of varying cosmetic products leads to a multitude of adverse effects. There is more awareness about cosmeceutics, cosmetic products and their adverse effects, and studies on the same are currently trending. Bibliometrics has become a prominent and growing field of research in recent years. The aim of this research was to assess bibliometric features and conduct systematic trend analysis on the literature available on cosmetics' adverse effects. We analyzed all the published documents that included the keywords "cosmetics" and "adverse effects" between 1957 and 2021. We performed a detailed scientometric and bibliometric assessment in this field. A total of 4127 articles were retrieved from the databases provided by Scopus, which most were original articles. The United States ranked first and dominated the literature with 1292 (31.44\%) documents followed by South Korea 7.47\%. Harvard medical school was the most productive institution $(1.16 \%)$. The study of the adverse effects of cosmetics should be supported and taken up by the researchers/authors from developing and underdeveloped countries.
\end{abstract}

Keywords: cosmetics; adverse effects; bibliometrics; publication analysis

\section{Introduction}

"Cosmetics are [sic] defined by their intended use as a material rubbed, poured, sprinkled, or sprayed on, introduced into, or otherwise applied to the human body for beautifying, promoting attractiveness, or altering the appearance". Cosmetics are mainly used to increase glamour and appeal, and play an important role in the development of an image and in the process of appearing presentable to others. At their rate of use, cosmetics heavily impact the skin and can show effective as well as ineffective results $[1,2]$. Linda B et al., in his study, found that $25 \%$ women use around 15 cosmetic products daily, adults use 9 cosmetic products daily and also found that around 1-3\% of the population are allergic to cosmetic ingredients [3]. Cosmetics and beauty products are not particularly beneficial to one's physical health and continued use can cause serious health adversities. The cosmetic ingredients used in beauty products have a direct impact on the human body's hormonal system, causing endocrine disruption [4]. Heavy metals are one of the most common ingredients in cosmetics, and they cause skin irritation and epithelial damage. The accumulation of heavy metals has a negative impact on mucous membranes [5].These adverse events are rising day by day because of the increased use of cosmetic products. Women are known to use more cosmetic products compared with men. 
A vast majority do not follow the instructions given in cosmetic packaging [6]. According to the literature, conducting cosmetic product awareness campaigns and encouraging the idea of cosmetovigilance can help to minimize adverse events [7]. "Bibliometrics is a novel and popular scientific field investigating academic literature and analyzing publication trends and patterns in a certain area" [8]. Despite the growing popularity of scientometric and bibliometric assessments of scientific evidence, there is no research in dermatology and medical literature that examines the bibliometric features of articles on cosmetic-related adverse reactions. The aim of this study was to conduct a systematic bibliometric review of the literature on the adverse effects of cosmetics and produce a trend analysis in this broad field.

\section{Materials and Methods}

Search tool and strategy

Study design: A retrospective bibliometric analysis was used.

Inclusion criteria: All the documents published between 1957 and April 2021 were included in the study. All the manuscripts were considered in this study including letters to the editor and note.

Exclusion criteria: Manuscript published after April 2021 were excluded from the study.

To acquire articles on the adverse effects of cosmetics across time, the Scopus database (https://www.scopus.com, 24 April 2021, Elsevier, Amsterdam, The Netherlands) was used. "Scopus ${ }^{\circledR}$ is the world's largest abstract and citation database for peer-reviewed literature, with the most comprehensive analysis of published papers in the field of health science" [9]. The descriptive bibliometric analysis was carried out using Scopus's built-in functions. ("Distribution of types of documents and the most prolific publications, authors, institutions, and countries"). In March 2021, the search was performed using the keywords "cosmetics" and "adverse effects" as a search term to retrieve all possible papers aggregated within the group from the Scopus ${ }^{\circledR}$ database. For the trend analysis of the average number of articles, pages, references, organizations, authors and citations each year, we exported all information with reference records (all article editors and references) from the Scopus database in CSV format into Microsoft Excel (Redmond, WA, USA), and used Excel's Generate Text feature and its statistical functions to determine yearly averages. We also produced bibliometric network maps that depicted the most commonly used keywords, as well as the relationships and connections between countries. In this research, we used the freeware resource VOSviewer (Centre for Science and Technology Studies, Leiden University, Leiden, The Netherlands) to create bibliometric network visualization maps. The role of the software is connecting the nodes in the network to the clusters; thus, in a way, a cluster is a set of nodes that are loosely related. As the value of this parameter grows, the number of clusters also increases. Each cluster is represented accordingly by a color. The terms that are more important have larger circles, and terms that were strongly related to each other were closer. Lines between terms indicate, by thickness, a stronger link between the two terms $[10,11]$.

\section{Results}

\subsection{Total Number of Publications}

The Scopus database produced 4127 documents during our search. It was found that 1004 items were "open access". A majority of the publications were "original articles" $(n=2948 ; 71.43 \%)$, followed by review $(n=802 ; 19.43 \%)$. The other most commonly published forms were book chapters and letters (2.64\% and 2.02\%, respectively) (Table 1$)$. 
Table 1. Document types in the scientific literature related to cosmetic adverse effects literature.

\begin{tabular}{cccc}
\hline SI. NO & Document Type & Number of Publications & \% \\
\hline 1 & Article & 2948 & 71.43 \\
\hline 2 & Review & 802 & 19.43 \\
\hline 3 & Book Chapter & 109 & 2.64 \\
\hline 4 & Letter & 91 & 2.20 \\
\hline 5 & Conference Paper & 80 & 1.94 \\
\hline 6 & Note & 45 & 1.09 \\
\hline 7 & Short Survey & 24 & 0.58 \\
\hline 8 & Editorial & 17 & 0.41 \\
\hline 9 & Book & 8 & 0.19 \\
\hline 10 & Retracted & 2 & 0.04 \\
\hline 11 & Total & 4122 & $100 \%$ \\
\hline
\end{tabular}

SI. NO = Serial Number.

The United States of America, with 1292 items, was the leading country contributing to the literature (31.40\%) followed by South Korea, Germany, United Kingdom and China $(7.46 \%, 6.85 \%, 6.78 \%$ and $6.67 \%$, respectively). The majority of countries ranked by the total number of publications were developed countries, and the least publications were from developing and under developed countries. India produced only $3.82 \%$ of all cosmetic adverse effect literature $(n=158$ articles) (Figure 1$)$.

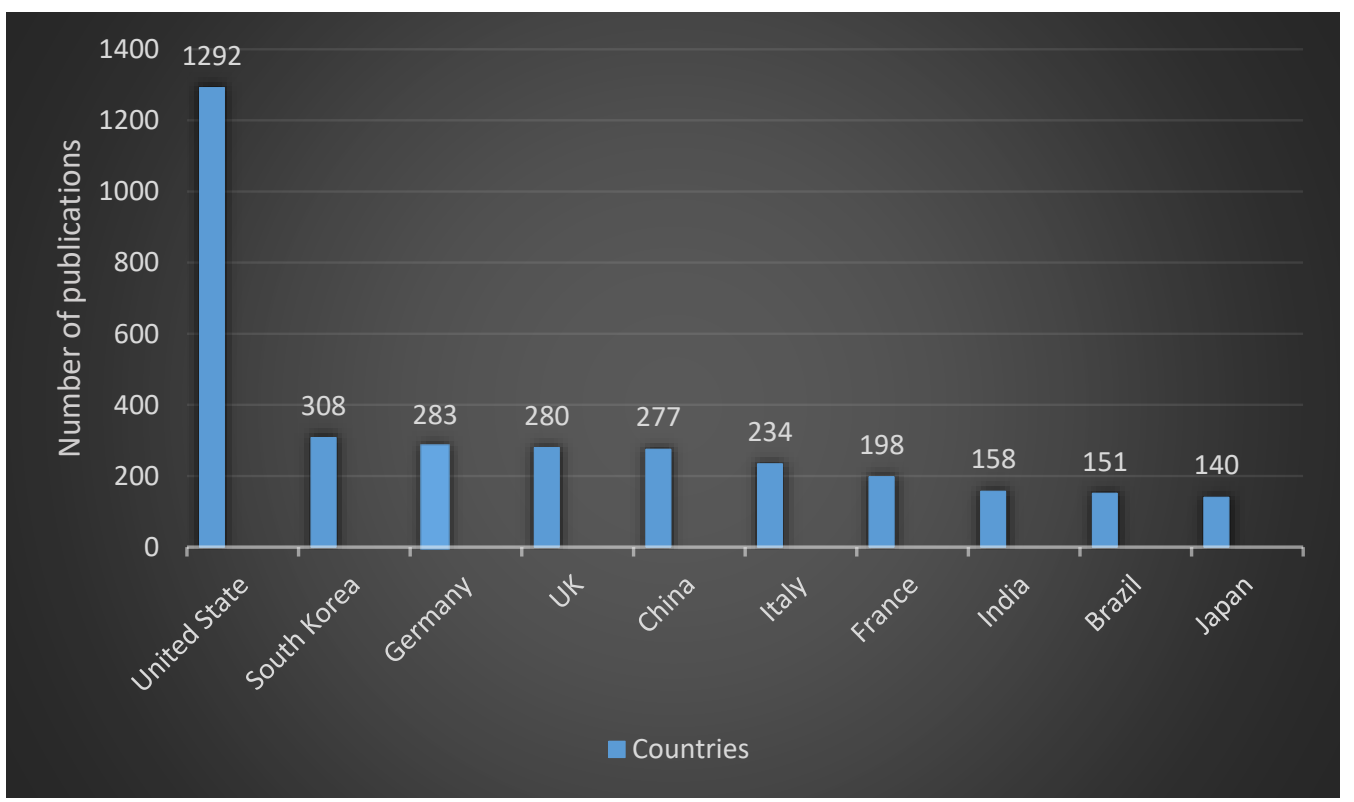

Figure 1. Top 10 countries publishing cosmetic-related adverse effect publications by the total number of documents.

\subsubsection{Research Areas, Journals, Institutions and Authors}

The most researched fields in the literature related to adverse effects of cosmetics were found to be medicine, followed by pharmacology, toxicology and pharmaceutics, as well as biochemistry, genetics and molecular biology $(78.04 \%, 15.41 \%$, and $9.93 \%)$ (Table 2). 
Table 2. The first ten research areas of the publications related to cosmetic adverse effects literature.

\begin{tabular}{cccc}
\hline SI. NO & Research Areas & Number of Publications & $\%$ \\
\hline 1 & Medicine & 3221 & 78.04 \\
\hline 2 & $\begin{array}{c}\text { Pharmacology, Toxicology } \\
\text { and Pharmaceutics }\end{array}$ & 636 & 15.41 \\
\hline 3 & $\begin{array}{c}\text { Biochemistry, Genetics and } \\
\text { Molecular Biology }\end{array}$ & 410 & 9.93 \\
\hline 4 & Environmental Science & 221 & 5.35 \\
\hline 5 & Chemistry & 141 & 3.41 \\
\hline 6 & Agricultural and Biological Sciences & 124 & 3.00 \\
\hline 7 & Chemical Engineering & 123 & 2.98 \\
\hline 8 & Engineering & 89 & 2.15 \\
\hline 9 & Immunology and Microbiology & 60 & 1.45 \\
\hline 10 & Physics and Astronomy & 51 & 1.23 \\
\hline
\end{tabular}

SI. $\mathrm{NO}=$ Serial Number.

Andersen, F.A., from Cosmetic Ingredient Review, Washington, D.C., United States, was found to be the most productive author, with 33 papers amounting to $0.79 \%$ of total, followed by Kim, B.J., from South Korea's Chung Ang University and Carruthers, J. from the University of British Columbia ( $0.65 \%$ and $0.41 \%$, respectively). A majority of the authors were from developed countries (Table 3).

Table 3. The first ten authors by record count.

\begin{tabular}{|c|c|c|c|c|c|}
\hline SI. NO & Author & Institutions & Country & Record Count & $\%$ \\
\hline 1 & Andersen, F. A. & $\begin{array}{l}\text { Cosmetic Ingredient Review, Washington, D.C., } \\
\text { United States }\end{array}$ & United States & 33 & 0.79 \\
\hline 2 & Kim, B. J. & South Korea's Chung-Ang University & South Korea & 27 & 0.65 \\
\hline 3 & Carruthers, J. & University of British Columbia & Canada & 17 & 0.41 \\
\hline 4 & Alam, M. & $\begin{array}{l}\text { Florida Center for Dermatology, St Augustine, } \\
\text { United States }\end{array}$ & United States & 16 & 0.38 \\
\hline 5 & Carruthers, A. & the University of British Columbia & Canada & 16 & 0.38 \\
\hline 6 & Cohen, J. L. & $\begin{array}{l}\text { Skin Dermatology and DermSurgery, Greenwood } \\
\text { Village, United StatesUniversity of California }\end{array}$ & United States & 16 & 0.38 \\
\hline 7 & Goldman, M. P. & Cosmetic Laser Dermatology, San Diego & United States & 16 & 0.38 \\
\hline 8 & Gold, M. H. & Gold Skin Care Center, Nashville & United States & 15 & 0.36 \\
\hline 9 & Goldberg, D. J. & $\begin{array}{c}\text { Icahn School of Medicine at Mount Sinai, New York, } \\
\text { United States Laser and Skin Surgery Center of } \\
\text { New York }\end{array}$ & United States & 14 & 0.33 \\
\hline 10 & Dover, J.S. & United States Yale University & United States & 13 & 0.31 \\
\hline
\end{tabular}

Harvard Medical School was found to be the most productive institution, with 48 items $(1.16 \%)$, followed by the University of British Columbia $(0.94 \%)$, whereas Northwestern University's Feinberg School of Medicine had the least number of contributions among the top ten institutions. Many of the organizations were from developed countries (Table 4). 
Table 4. The top ten institutions by number of publications in the literature related to cosmetic adverse effects literature.

\begin{tabular}{cccc}
\hline SI. NO & Institutions & Document Number & \% \\
\hline 1 & Harvard Medical School & 48 & 1.16 \\
\hline 2 & University of British Columbia & 39 & 0.94 \\
\hline 3 & Icahn School of Medicine at Mount Sinai & 39 & 0.94 \\
\hline 4 & University of California, Los Angeles & 39 & 0.94 \\
\hline 5 & Cosmetic Ingredient Review & 35 & 0.84 \\
\hline 6 & University of California, San Diego & 35 & 0.84 \\
\hline 7 & University of California, San Francisco & 33 & 0.79 \\
\hline 8 & David Geffen School of Medicine at UCLA & 32 & 0.77 \\
\hline 9 & University of Miami Leonard M. Miller School & 31 & 0.75 \\
\hline 10 & $\begin{array}{c}\text { Northwestern University's Feinberg School } \\
\text { of Medicine }\end{array}$ & 30 & 0.72 \\
\hline
\end{tabular}

SI. NO = Serial Number.

The Journal of Cosmetic Dermatology was the leading journal contributing to the literature on the adverse effects of cosmetics, and covered $4.16 \%$ of all documents, followed by the journals Dermatologic Surgery and Aesthetic Surgery (3.85\% and 3.17\%, respectively) (Table 5).

Table 5. The top ten journals by the number of published documents.

\begin{tabular}{|c|c|c|c|}
\hline SI. NO & Journal Name & Number of Publications & $\%$ \\
\hline 1 & Journal of Cosmetic Dermatology & 172 & 4.17 \\
\hline 2 & Dermatologic Surgery & 159 & 3.85 \\
\hline 3 & Aesthetic Surgery Journal & 131 & 3.17 \\
\hline 4 & Journal of Cosmetic And Laser Therapy & 115 & 2.78 \\
\hline 5 & Journal of Drugs In Dermatology & 83 & 2.01 \\
\hline 6 & Plastic and Reconstructive Surgery & 81 & 1.96 \\
\hline 7 & International Journal of Toxicology & 74 & 1.79 \\
\hline 8 & Aesthetic Plastic Surgery & 63 & 1.52 \\
\hline 9 & $\begin{array}{l}\text { Journal of The American Academy } \\
\text { of Dermatology }\end{array}$ & 62 & 1.50 \\
\hline 10 & $\begin{array}{c}\text { Dermatologic Surgery Official Publication for } \\
\text { American Society for Dermatologic Surgery } \\
\text { Et Al }\end{array}$ & 46 & 1.11 \\
\hline
\end{tabular}

SI. NO = Serial Number.

\subsubsection{Progression of Publications and Citations}

We conducted a citation review of the literature on the adverse effects of cosmetics over the last decade's 4127 articles. The most cited article was entitled "Bacterial Silver resistance: Molecular Biology and Uses and Misuses of Silver Compounds" by Silver, S., published in FEMS Microbiology Reviews, was cited 935 times, followed by "Chemistry, Bio-Chemistry, and Safety of Acrylamide: a Review" by Friedman, M., published in the Journal of Agriculture Chemistry, with 874 citations in 2003. The year 2003 had the most publications, i.e. three of the ten most cited articles, with 2471 total citations (Table 6). 
Table 6 . The ten most cited publications in cosmetic adverse effects literature.

\begin{tabular}{|c|c|c|c|c|c|}
\hline SI. NO & Article & Author & Journal Name & Total Citations & Year of Publication \\
\hline 1 & $\begin{array}{l}\text { Bacterial Silver Resistance: Molecular Biology and Uses and } \\
\text { Misuses of Silver Compounds }\end{array}$ & Silver, S. & FEMS Microbiology Reviews & 935 & 2003 \\
\hline 2 & Chemistry, Biochemistry, and Safety of Acrylamide. A Review & Friedman, M. & $\begin{array}{l}\text { Journal of Agricultural and } \\
\text { Food Chemistry }\end{array}$ & 874 & 2003 \\
\hline 3 & $\begin{array}{l}\text { Emerging Organic Contaminants in Groundwater: a Review of } \\
\text { Sources, Fate and Occurrence }\end{array}$ & Lapworth, D.J., et al. & Environmental Pollution & 872 & 2012 \\
\hline 4 & Silver Nanoparticle Applications and Human Health & Ahamed, M., et al. & Clinica Chimica Acta & 841 & 2010 \\
\hline 5 & Safety Assessment of Esters of p-Hydroxybenzoic Acid (Parabens) & Soni, M.G., et al. & Food and Chemical Toxicology & 664 & 2005 \\
\hline 6 & $\begin{array}{l}\text { Pharmaceuticals, Personal Care Products, and Endocrine } \\
\text { Disruptors In Water: Implications for the Water Industry }\end{array}$ & Snyder, S.A., et al. & $\begin{array}{l}\text { Environmental } \\
\text { Engineering Science }\end{array}$ & 662 & 2003 \\
\hline 7 & $\begin{array}{c}\text { Application of the Threshold of Toxicological Concern (TTC) to the } \\
\text { Safety Evaluation of Cosmetic Ingredients }\end{array}$ & Kroes, R., et al. & Food and Chemical Toxicology & 586 & 2007 \\
\hline 8 & Endocrine Disrupting Chemicals And Disease Susceptibility & Schug, T.T., et al. & $\begin{array}{l}\text { Journal of Steroid Biochemistry } \\
\text { and Molecular Biology }\end{array}$ & 580 & 2011 \\
\hline 9 & $\begin{array}{l}\text { Cyclosporin: A Review of its Pharmacodynamic and } \\
\text { Pharmacokinetic Properties, and Therapeutic Use in } \\
\text { Immunoregulatory Disorders }\end{array}$ & Faulds, D., et al. & Drugs & 466 & 1993 \\
\hline 10 & $\begin{array}{l}\text { The Relative Risk of Ulcerative Keratitis among Users of } \\
\text { Daily-Wear and Extended-Wear Soft Contact Lenses }\end{array}$ & Schein, O.D., et al. & $\begin{array}{l}\text { New England Journal } \\
\text { of Medicine }\end{array}$ & 456 & 1989 \\
\hline
\end{tabular}

SI. NO = Serial Number. 


\subsubsection{Bibliometric Network Analysis}

We noticed that the most commonly used keywords in this study were "human", "humans", "cosmetic techniques" and "adverse effects", after conducting a systematic keyword study. We created a bibliometric keyword network visualization map with the keyword "human" in the middle and connected it to the other keywords (Figure 2).

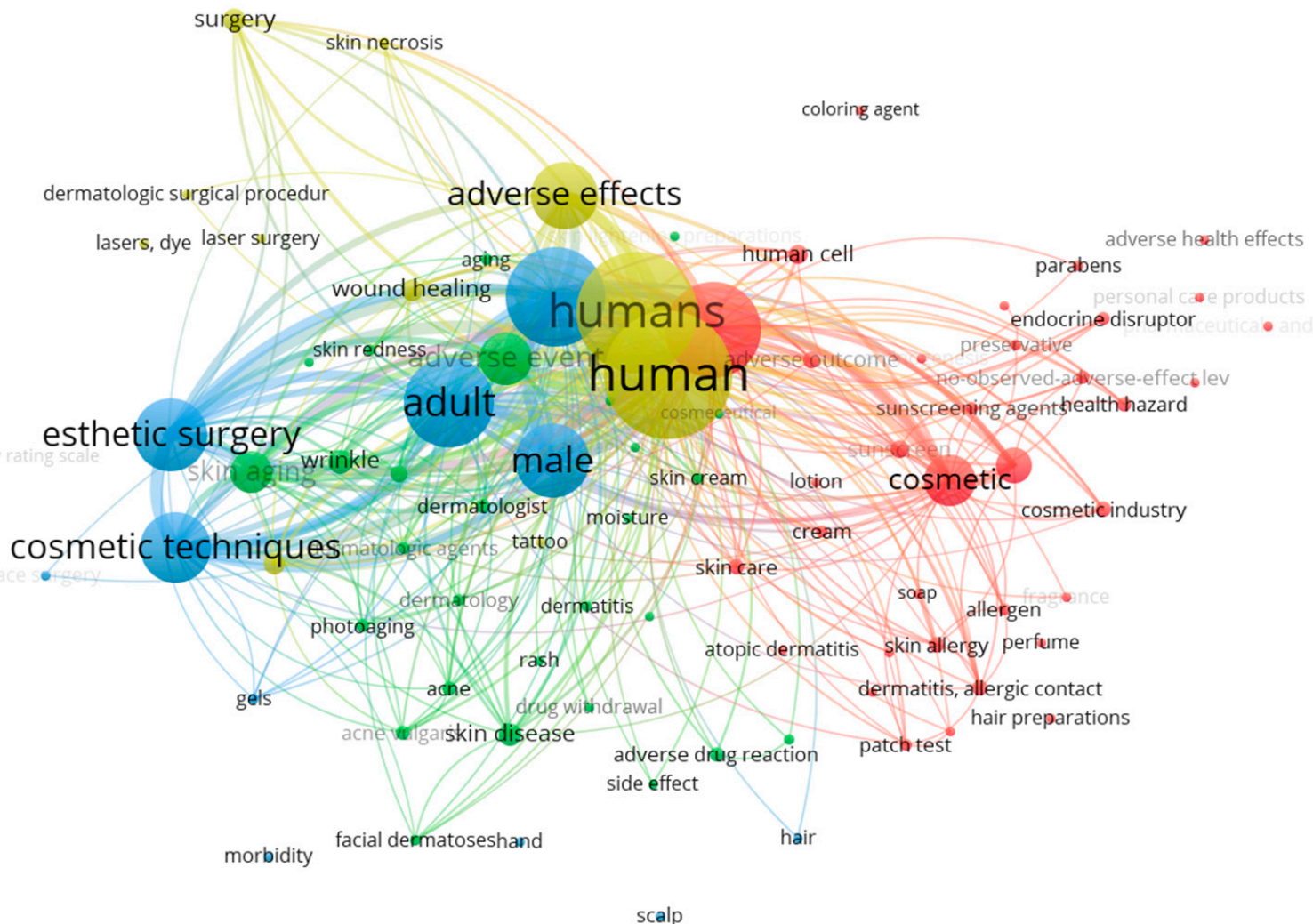

Figure 2. Keyword network of cosmetic adverse effects literature.

We also created a bibliometric countries network visualization map of produced documents; this revealed four main centers, including USA, China, the United Kingdom and South Korea, in which the United States of America was in the middle and linked to the other countries as a result of our comprehensive country analysis (Figure 3).

We found that the maximum number of publications (513) are in the year 2015 (Figure 4). 


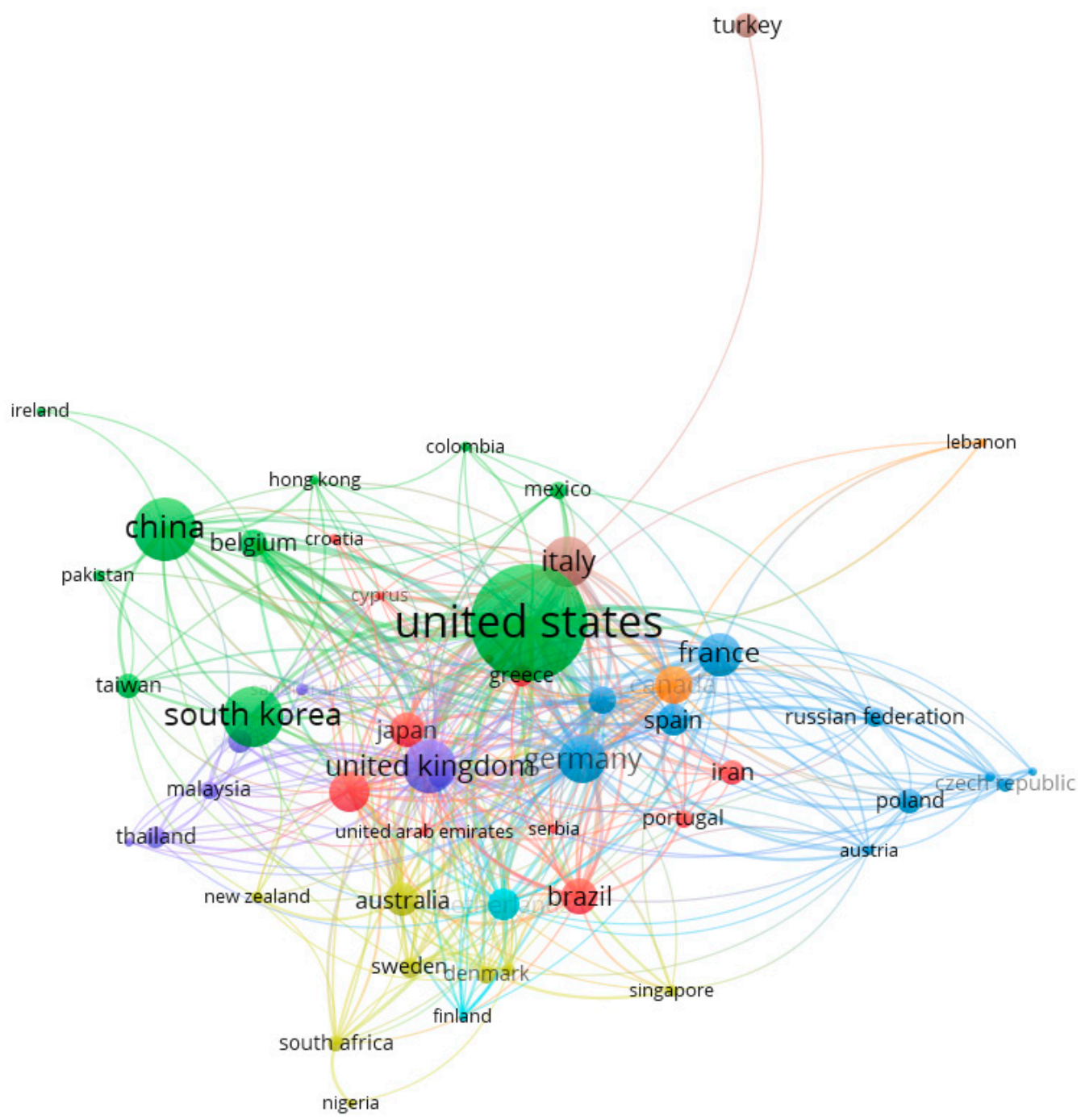

Figure 3. Countries network of literature on the adverse effects of cosmetics.

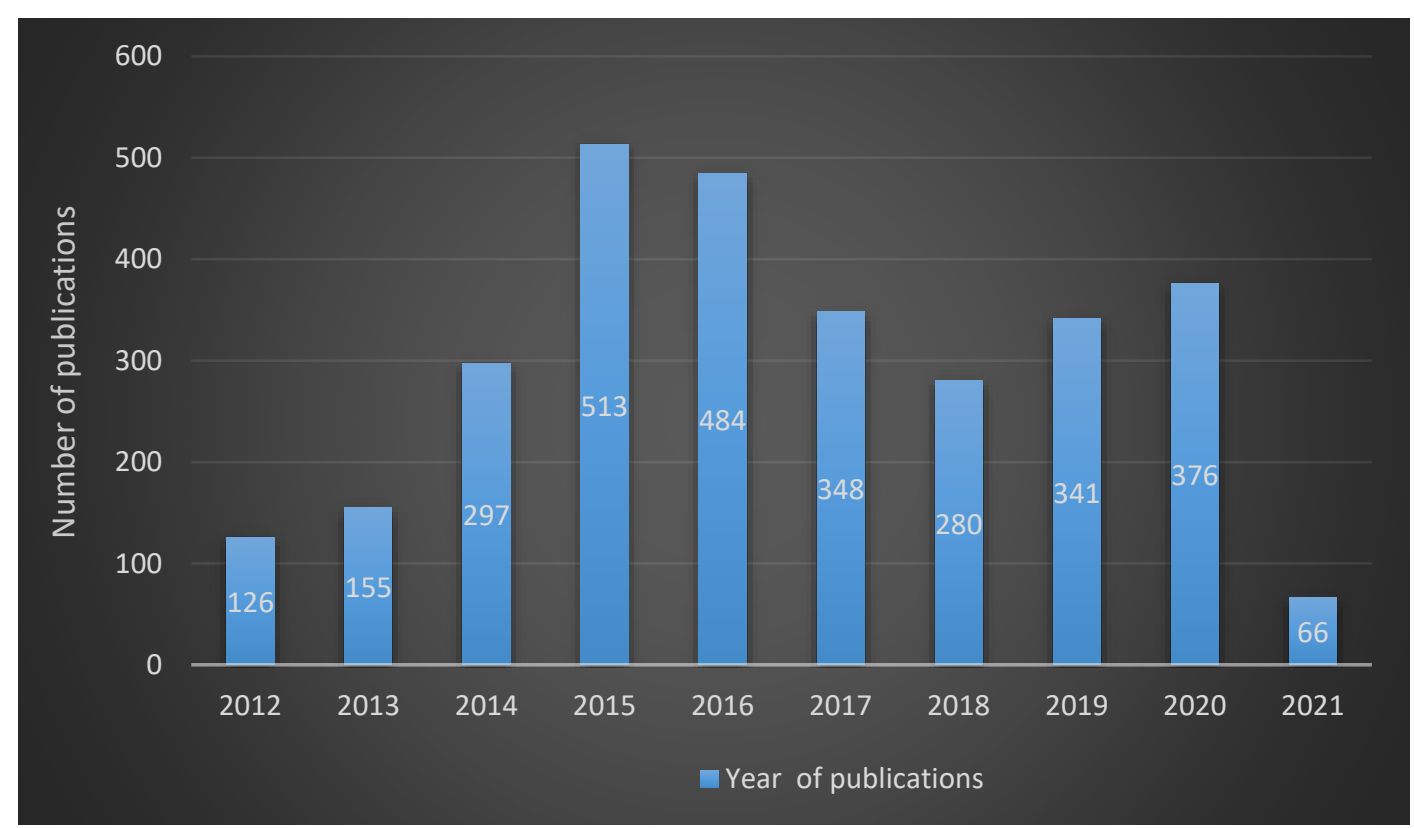

Figure 4. Years, with their number of publications. 


\section{Discussion}

The global cosmetic industry is estimated to be worth about $\$ 20$ billion dollars today [12]. The cosmetic industry has seen tremendous growth in the last 20 years, resulting in a wide variety of products to protect and moisturise skin, as well as fight inflammation and signs of ageing [13]. The cosmetics industry is a highly creative industry and contributes significantly to national and regional economies around the world [14]. Innovation is one of the basic principles in this field. Women, in particular, use beauty products that may contain harmful cosmetic ingredients [12].

"Cosmetics are preparations that are applied directly to the human skin, hair, and nails, however, recent concerns about their safety have been increasing". Metals in cosmetics may be retained and absorbed into the bloodstream, causing harmful effects in various organs [15]. Preservatives, stabilisers and mineral pigments are applied to cosmetic products to improve their consistency and quality. In order to obtain a better shine in some mineral pigments, glitter and dye are added to these products. Any of these substances can cause allergic reactions, irritation and harm to human health [5]. Acute toxicity, skin irritation, eye irritation, skin sensitization, sub-acute toxicity, mutagenicity/genotoxicity, type IV hypersensitivity, contact urticaria and other adverse effects can occur due to the use of cosmetics [16]. Irritant contact dermatitis is the most prevalent problem associated with the use of cosmetics. [17]. Perfumes, nail polish and other skincare items stay on the skin for longer periods of time and might cause allergic reactions [18]. "Skin care products are [sic] a kind of umbrella term covering cleansing, changing appearance, perfuming, changing body odor, protecting and keeping the skin in good condition" [19]. "Perfume is a mixture of fragrant essential oils or aroma compounds, fixatives and solvents, used to give the human body, animals, food, objects, and living-spaces an agreeable scent." [20]. "A fragrance consists of volatile chemicals with a molecular weight of less than $300 \mathrm{Da}$ that humans perceive through the olfactory system" [21].

Some of the common cosmetics products and their toxicities are:

Shampoos: Hydrogen peroxide solutions and ammonium persulfate, which are active chemicals in hair bleaching products, can trigger Types I and IV allergic contact reactions [12].

Skin lightening agent: Hydroquinone (HQ), a skin lightening agent, has been identified as one of the most dangerous substances. Reports of ochronosis and possible mutagenicity have been discovered. Ochronosis is a rare HQ side effect, characterised by a gradual darkening of the area to which a cream containing high concentrations of HQ has been applied for many years. It causes irritation, burning and redness of the skin [22].

Henna dye, hair dye: Henna dye and hair dye contains the ingredient PPD (pphenylenediamine) which can cause allergic reactions including blisters, surface oozing, weepy dermatitis, eczematous dermatitis, pruritic dermatitis, swelling and erythematous rashes on the skin [23].

Deodorants or antiperspirants: Ingredients or fragrances which are present in deodorants or antiperspirants may cause allergic reactions. Fragrances enter the body, through the nose, directly into the brain and can cause headaches, fatigue, dizziness and irritation to eyes, nose and throat. When fragrances are found in the air, they can cause airborne contact dermatitis. Phthalates present in fragrances are suspected hormone disrupters. Fragrances which are present in perfumes can cause allergic reactions, headaches and asthma [24].

The adverse effects associated with ingredients used in the formulation of cosmetics:

BHA and BHT: In moisturizers and lipsticks, synthetic chemicals such as BHA (butylated hydroxyl anisole) and BHT (butylated hydroxyl toluene) can cause allergic reactions to the skin. The International Agency for Research on Cancer has classified BHA as a human carcinogen. BHT in high concentrations can imitate hormones like oestrogen, and block the development of male sex hormones, causing reproductive problems [12,25]. When applied in high concentrations, moisturisers can irritate and exfoliate the skin [18].

Parabens: Preservatives are used to protect cosmetics from microbial contamination. The most commonly used preservative are parabens, which penetrate the skin and are 
suspected to interfere with hormonal functions. They imitate hormones like oestrogen and interfere with male reproductive function. When methylparaben is applied to the skin, it combines with other chemicals present in cosmetics, causing skin aging [12,26].

Siloxanes: Siloxanes are silicone-based chemicals that are used to soften and smooth a variety of cosmetic products. They are commonly used in facial treatments and moisturizers. Cyclotetrasiloxane and cyclopentasiloxane are two extensively used siloxanes that are hazardous to human health. Cyclotetrasiloxane is classified as an endocrine disruptor that interacts with human hormone function and, as a potential reproductive toxicant, may damage human fertility [12,27].

Adverse effects associated with heavy metals in cosmetics:

Heavy metals: Heavy metals present in cosmetics can accumulate in the body over a long period and can cause contact dermatitis, cancer, vomiting, reproductive disorders and headaches.

Lead: Lead is a heavy metal that can be found as an impurity in lipsticks and eye powders such as kajal, and has been associated with high blood lead levels in women and children, which are toxic to the body. Pregnant women are at higher risk because it can easily cross the placenta and reach the foetus' brain. It can also be transferred to infants through lactating mothers' milk [12,28].

Cadmium: Cadmium is a heavy metal that is present in most body and hair creams; it is absorbed into the body through dermal contact and stored in the kidney and liver. If ingested in high amounts it may lead to vomiting and severe stomach irritations. Exposure over a long time may lead to kidney damage [12].

Mercury: Mercury is a major ingredient used in most creams, skin lightening soaps and eye makeup. It is found in cosmetics in organic and inorganic forms. Kidneys are the major site of deposition of inorganic mercury; kidney damage is a common side effect of the inorganic mercury found in lotions and skin whitening soaps. Inorganic mercury poisoning has been reported in the USA, Mexico, Africa and Europe [29]. Because of health concerns, the US FDA has restricted nine ingredients from cosmetics, while the EU has banned over 1000 ingredients. The use of cosmetics should be limited, and people should be informed about the composition and application of cosmetics to reduce their harm [30]. To promote changes in the manufacture, marketing and use of cosmetic products by the general population, it is critical to apply a standard cosmetovigilance over the world [12,31]. "Cosmetovigilance is a model of safety monitoring of cosmetics. It can be considered as one of the elements in public health activities" [32]. This public health policy is a legal way of gathering information on the safety of cosmetics and their ingredients, in order to reduce the risks associated with cosmetics use [12,31].

Cosmetovigilance systems, in different countries, are as followed:

Europe: Cosmetics products sold in the European Union (EU) should meet stringent safety and quality requirements. The Cosmetics Regulation (EC) No. 1223/2009 of the European Union (EU) requires companies to collect and analyse reports of adverse health consequences (undesirable effects) from the cosmetic products they market [33,34].

Netherlands: The Netherlands Food and Consumer Product Safety Authority and the Netherlands Ministry of Health have agreed to monitor the adverse effects of cosmetics and have expressed a willingness to cooperate toward the establishment of a cosmetovigilance network [34].

Canada: In Canada, healthcare professionals and consumers are encouraged to report side effects as per their Natural Health Products (NHP) Regulations, which started in January 2004. The NHP is in charge of ensuring that all cosmetic products are properly licenced, sufficient evidence for safety and efficacy is provided, appropriate labelling is provided, good manufacturing practises are followed, ADRs are reported, clinical trials related to cosmetic products are kept up to date and be the source of information for product recalls to all consumers. There are reporting forms, with which adverse events must be reported within 15 days [35]. 
USA: In the USA cosmetics labelling and purity have been made necessary for the marketing of cosmetics by the US Food and Drug Administration. As a result, it is the responsibility of the cosmetics manufacturer in the United States to provide high-quality cosmetic products [36].

Germany and Sweden: These are the two countries that have a formal cosmetovigilance system. In Germany, information on human health effects after exposure to any kind of substance, including cosmetics, is submitted to the BfR (Budensinstitut fur Risikobewertun) in Berlin. Sweden has a Cosmetovigilance Center, which was established in 1989. The Department of Cosmetics, which is part of the MPA (Medical Products Agency) located in Uppsala, is in charge of it. It represents the Swedish national authority, which is responsible for collecting ACRs reported by various professional categories/persons (mostly general practitioners and medical specialists) [37].

India: Due to a lack of a well-organized reporting system in India, undesirable reactions to cosmetic products go unreported. Cosmetic-related adverse reactions have so far remained undetected. It is time for India to establish a formal cosmetovigilance system [38].

Most of the authors and organisations on the top ten productive lists were from developed countries, according to our findings. We found that Harvard Medical School was first among the top ten institutions reporting research investigating adverse cosmetics effects (1.16) (Table 4). We found that the maximum number of publications (513) are in the year 2015 (Figure 4). There has been no study investigating the bibliometric features of literature on adverse effects related to cosmetics. So far, there has been no study in the literature with which to compare our results.

\section{Conclusions}

Due to increasing consciousness about beauty, people are using more cosmetic products, which results in increasing adverse events. Cosmetic and beauty products are not that virtuous for health, as they contain more than 10,000 ingredients that can be linked to disease. Due to the continues use of cosmetics, people are exposed to adverse effects such as contact dermatitis, allergy, redness of skin, type IV hypersensitivity etc. Cosmetic ingredients used in cosmetic products have a direct effect on the hormonal systems of the human body. The public should be warned about the presence of toxic ingredients in cosmetic products. It is important to implement a global cosmetovigilance system to encourage changes in cosmetic product manufacturing, marketing and use by the general population. Such a system would increase the safety of these products and their ingredients and prevent the adverse effects of these products. It is important to carry out studies investigating adverse effect of cosmetics; we suggest that researchers across the globe, especially from developing and underdeveloped countries, perform more and more novel studies, particularly on cosmetics' adverse effects.

Author Contributions: Conceptualization: V.S.L.; methodology: M.N.; software: M.N.; validation, V.S.L., S.S.P. and D.S.; formal analysis: S.S.P.; investigation: D.S.; resources: M.N.; data curation: M.N.; writing—original draft preparation: M.N. and V.S.L.; writing—review and editing: D.S. and S.S.P.; visualization: D.S.; supervision: V.S.L.; project administration: V.S.L., D.S. and S.S.P. All authors have read and agreed to the published version of the manuscript.

Funding: This research received no external funding.

Institutional Review Board Statement: Not Applicable.

Informed Consent Statement: Not Applicable.

Data Availability Statement: There is no data supporting reported results generated during the study.

Conflicts of Interest: The authors declare no conflict of interest in this work. 


\section{References}

1. Getachew, M.; Tewelde, T. Cosmetic Use and Its Adverse Events among Female Employees of Jimma University, Southwest Ethiopia. Ethiop. J. Health Sci. 2018, 28, 717-724. [CrossRef]

2. Mansor, N.; Efni binti, D.; Yaacob, M.R. Cosmetic Usage in Malaysia: Understanding of the Major Determinants Affecting the Users. Int. J. Bus. Soc. Sci. 2010, 1, 273-281.

3. Linda, B.; Sedlewicz, B.S. Cosmetic preservatives: Friend or foe? Skinmed 2005, 4, 8-100.

4. Gowha, S.A. Harmful effects of beauty care products on human health. Int. J. Med. Sci. Public Health 2018, 7, 1-8.

5. Kaličanin, B.; Velimirović, D. A Study of the Possible Harmful Effects of Cosmetic Beauty Products on Human Health. Biol. Trace Elem. Res. 2016, 170, 476-484. [CrossRef]

6. Shiraz, A.; Rahaman, A.M. Study on Awareness about Adverse Health Effects of Cosmetics among Females of Different Age Groups. J. Med. Sci. Clin. Res. 2016, 7, 503-510. [CrossRef]

7. Bilal, A.I.; Tilahun, Z.; Shimels, T.; Gelan, Y.D.; Osman, E. Cosmetics Use-Related Adverse Events and Determinants among Jigjiga Town Residents, Eastern Ethiopia. Dermatol. Ther. 2017, 7, 143-153. [CrossRef]

8. Şenel, E.; Demir, E.; Alkan, R.M. Bibliometric analysis on global Behçet disease publications during 1980-2014: Is there a Silk Road in the literature? J. Eur. Acad. Derm. Venereol. 2017, 31, 518-522. [CrossRef] [PubMed]

9. Scopus. Available online: https://www.elsevier.com/en-in/solutions/scopus (accessed on 24 April 2021).

10. van Eck, N.J.; Waltman, L. VOSviewer Manual. Available online: https://www.vosviewer.com/documentation/Manual_ VOSviewer_1.6.8.pdf (accessed on 29 April 2021).

11. Mattos, F.D.F.; Perazzo, M.F.; Vargas Ferreira, F.; Martins-Júnior, P.A.; Paiva, S.M. Top 100 most-cited papers in core dental public health journals: Bibliometric analysis. Community Dent. Oral Epidemiol. 2021, 49, 40-46. [CrossRef]

12. Khan, A.; Alam, M. Cosmetics and their associated adverse effects: A review. J. Appl. Pharm. Sci. Res. 2019, 2, 1-6. [CrossRef]

13. Rodrigues, F.; Carretero, A.S. Cosmetics. 2018. Available online: https://www.sciencedirect.com/topics/agricultural-andbiological-sciences/cosmetics (accessed on 4 April 2021).

14. Singh, B.M.; Jain, A.; Mishra, A. Cosmetic Regulations in India vs. Globally and Challenges in Harmonization. Int. J. Pharm. Sci. Drug Res. 2018, 10, 150-157. [CrossRef]

15. Borowska, S.; Brzóska, M.M. Metals in cosmetics: Implications for human health. J. Appl. Toxicol. 2015, 35, 551-572. [CrossRef] [PubMed]

16. Nigam, P.K. Adverse reactions to cosmetics and methods of testing. Indian J. Derm. Venereol. Lepro. L 2009, 75, 10-18. [CrossRef] [PubMed]

17. Draelos, Z.D. Facial skin care products and cosmetics. Clin. Derm. 2014, 32, 809-812. [CrossRef]

18. Dooms-Goosens, A. Cosmetics as causes of allergic contact dermatitis. Cutis 1993, 52, 316-320.

19. Kottner, J.; Lichterfeld, A.; Blume-Peytavi, U. Maintaining skinintegrity in the aged: A systematic review. Br. J. Dermatol. 2013, 169, 528-542. [CrossRef]

20. Ahmed, N.; Naziya, S.; Supriya, K.; Ahmed, S.A.; Kalyani, G.; Ganeshwari, S.; Rao, K.N.V.; Dutt, K.R. A Review on Perfumery. World J. Pharm. Sci. 2019, 7, 56-68.

21. Sowndhararajan, K.; Kim, S. Influence of Fragrances on Human Psychophysiological Activity: With Special Reference to Human Electroencephalographic Response. Sci. Pharm. 2016, 84, 724-752. [CrossRef]

22. Donsing, P.; Viyoch, J. Thai Breadfruit's Heartwood Extract: A New Approach to Skin Whitening. Srinakharinwirot Sci. J. 2008, 24, 9-23.

23. Nigam, P.K.; Saxena, A.K. Allergic contact dermatitis from henna. Contact Dermat. 1988, 18, 55-56. [CrossRef]

24. Bridges, B. Fragrance: Emerging health and environmental concerns. Flavour Fragr. J. 2002, 17, 361-371. [CrossRef]

25. Schrader, T.J.; Cooke, G.M. Examination of selected food additives and organochlorine food contaminants for androgenic activity in vitro. Toxicol. Sci. 2008, 53, 278-288. [CrossRef]

26. Darbre, P.D.; Aljarrah, A.; Miller, W.R.; Coldham, N.G.; Sauer, M.J.; Pope, G.S. Concentrations of Parabens in human breast tumours. J. Appl. Toxicol. 2004, 24, 5-13. [CrossRef] [PubMed]

27. Curtis, J.; Colas, A. Medical applications of silicones. In Biomaterials Science; Ratner, B.D., Man, A.S.H., Schoen, F.J., Lemons, J.E., Eds.; Elsevier/Academic Press: New York, NY, USA, 2004.

28. Zakaria, A.; Ho, Y.B. Heavy metals contamination in lipsticks and their associated health risks to lipstick consumers. Regul. Toxicol. Pharmacol. 2015, 73, 191-195. [CrossRef]

29. Mehrdad, R.R.; Mehravar, R.R.; Sohrab, K.; Moghadamnia, A.A. Current approaches of the management of mercury poisoning: Need of the hour. DARU J. Pharm. Sci. 2014, 22, 22-46.

30. Jadhav, V.; Dhande, S.; Kadam, V. Cosmetic's side effects. World J. Pharm. Pharm. Sci. 2016, 6, 327-343.

31. Pereira, J.X.; Pereira, T.C. Cosmetics and its Health Risks. Glob. J. Med. Res. 2018, 18, 63-70. [CrossRef]

32. Lucca, J.M.; Joseph, R.; Al Kubaish, Z.H.; Al-Maskeen, S.M.; Alokaili, Z.A. An observational study on adverse reactions of cosmetics: The need of practice the Cosmetovigilance system. Saudi Pharm. J. 2020, 28, 746-753. [CrossRef]

33. Renner, G.; Audebert, F.; Burfeindt, J.; Calvet, B.; Caratas-Perifan, M.; Leal, M.E.; Gorni, R.; Long, A.; Meredith, E.; O’Sullivan, Ú.; et al. Cosmetics Europe Guidelines on the Management of Undesirable Effects and Reporting of Serious Undesirable Effects from Cosmetics in the European Union. Cosmetics 2017, 4, 1. [CrossRef]

34. Vigan, M.; Castelain, F. Cosmetovigilance: Definition, regulation, and use "in practice". Eur. J. Derm. 2014, 24, 643-649. [CrossRef] 
35. MedEffect Canada. Available online: https://www.canada.ca/en/health-canada/services/drugs-health-products/medeffectcanada.html (accessed on 14 June 2021).

36. Nohynek, G.J.; Antignac, E.; Re, T.; Toutain, H. Safety assessment of personal care products/ cosmetics and their ingredients. Toxicol. Appl. Pharmacol. 2010, 243, 239-259. [CrossRef] [PubMed]

37. Sautebin, L. A cosmetovigilance survey in Europe. Pharm. Res. 2007, 55, 455-460. [CrossRef] [PubMed]

38. Udupa, N.; Ligade, V. Need of Cosmetovigilance in India. Value Health 2016, 19, 836. [CrossRef] 